\title{
Risk Factors of Pathological Unconjugated Hyperbilirubinemia among Yemeni Newborn
}

\author{
NAFISA H. Al-JAIFI, Ph.D.*; ARWA A. Al-HARAZI, M.D.*; ALI F. Al-ERYANI, M.D.* and \\ AHLAM A. SOWILEH, M.Sc.** \\ The Department of Pediatrics, Faculty of Medicine and Health Sciences, Sana'a University* and \\ The Department of Pediatric Specialist, Saudi German Hospital Sanaa**
}

\begin{abstract}
Background: Jaundice is a clinical condition that is often present in pediatric practice and constitutes one of the major issues within the neonatal period and it is either physiological or pathological. Although most newborn who have jaundice are otherwise healthy, they need close monitoring for serum bilirubin level as bilirubin is potentially toxic to the central nervous system. Risk factors may be maternal or neonatal in origin. This preliminary study focuses on the detection of the risk factors of pathological unconjugated hyperbilirubinemia due to lack of information on this topic in Yemen.
\end{abstract}

Aim of Study: To determine the most common aetiology and risk factors of pathological unconjugated hyperbilirubinemia and their relation to serum bilirubin.

Patients and Methods: The study was prospective crosssectional descriptive study of newborns with pathological unconjugated hyperbilirubinemia admitted to neonatal intensive care unit (NICU) at Al-Thawra General Modern Teaching Hospital and Al-Sabeen Maternity and Childhood Teaching Hospital during a period of 12 months starting on June 2012 to end of May 2013. Of the total admitted cases, two hundred cases were selected according to the inclusion and exclusion criteria. Data was collected, tabulated and analyzed by using Statistical Package for the Social Sciences (SPSS) version 20.

Results: The risk factors of pathological hyperbilirubinemia were Neonatal sepsis which was the most common aetiology and associated risk factor and was present in $70 \%$ of the cases, $\mathrm{ABO}$ incompatibility was present in $14 \%$ of the cases, $\mathrm{Rh}$ incompatibility was present in $8 \%$ of the cases, Cephalohaematoma (excessive bruising) was present in $6 \%$ of the cases, and G6PD deficiency was present in $2 \%$ of the cases.

Conclusion: Pathological unconjugated hyperbilirubinemia is one of the major problems in neonatal morbidity and mortality in Yemen. Neonatal sepsis was the commonest aetiology and associated risk factor of pathological hyperbilirubinemia and the major cause of death in this study. We need to do early screening for detecting hyperbilirubinemia and we need to adopt early essential newborn care and resuscitation guideline on a national level to conduct appropriate management.

Correspondence to: Dr. Nafisa H. Al-Jaifi, E-Mail: naaljaifi@gmail.com
Key Words: Unconjugated hyperbilirubinemia - NewbornNeonatal intensive care unit - Phototherapy Neonatal sepsis - Risk factors.

\section{Introduction}

JAUNDICE is a clinical condition that is often present in pediatric practice and constitutes one of the major issues within the neonatal period [1] Neonatal hyperbilirubinemia is extremely common. Jaundice in neonates is common affecting nearly $60 \%$ of fullterm and $80 \%$ of preterm neonates during the first week of life [2]. Neonatal Hyperbilirubinemia is extremely common as almost every newborn develops unconjugated serum bilirubin level of more than $30 \mathrm{umol} / \mathrm{L}(1.8 \mathrm{mg} / \mathrm{dl})$ during the first week of life [1] . Neonatal Hyperbilirubinemia can be both physiological and pathological processes in newborns. Although most newborn with jaundice are otherwise healthy, they need to be monitored because bilirubin is potentially toxic to the central nervous system [1]. However, few term newborns with hyperbilirubinemia have serious underlying pathology. Jaundice is considered pathologic if it presents within the first 24 hours after birth, the total serum bilirubin level rises by more than $5 \mathrm{mg}$ per $\mathrm{dL}(86 \mathrm{~mol}$ per $\mathrm{L})$ per day or is higher than $17 \mathrm{mg}$ per dL (290mol per L) [3]. The common risk factors for unconjugated hyperbilirubinemia include fetal-maternal incompatibility, prematurity, low birth weight, previous sibling with history of jaundice, breastfeeding, cephalohaematoma, trauma from instrumental delivery, or delayed meconium $[4,5]$. Hyperbilirubinemia may require therapy, which is mainly in the form of phototherapy or exchange transfusion [6]. No information was found about pathological unconjugated hyperbilirubinemia in Yemen. The aim of this study was to determine the most common aetiology and risk factors of pathological unconju- 
gated hyperbilirubinemia, and their relation to serum bilirubin.

\section{Patients and Methods}

The study was prospective cross-sectional descriptive of newborn with pathological unconjugated hyperbilirubinemia admitted to neonatal intensive care unit (NICU) at Al-Thawra General Modern Teaching Hospital and Al-Sabeen Maternity and Childhood Teaching Hospital from June 01, 2012 to May 31, 2013. A total number of 1183 of newborns were admitted to the NICU during the period of 12 months. Of them 200 cases were selected according to the inclusion and exclusion criteria. The inclusion criteria included the following, (1) Clinical jaundice appearing in the first 24 hours of life. (2) Increases in the level of total bilirubin of more than $8.5 \mathrm{umol} / 1(0.5 \mathrm{mg} / \mathrm{dl})$ per hour or $85 \mathrm{umol} / 1(5 \mathrm{mg} / \mathrm{dl})$ per 24 hours. (3) Total bilirubin of more than $331.5 \mathrm{umol} / 1(19.5 \mathrm{mg} / \mathrm{dl})$. The Exclusion criteria were all newborn with physiological or conjugated hyperbilirubinemia. The study collected detailed case history for all the newborn which included comprehensive clinical examination and specific investigations, specifically serum bilirubin level (total, direct and indirect levels), blood group and Rh typing of baby and mother, hemoglobin levels, complete blood picture, septic screening which included CRP, band cells, reticulocyte count, Coombs test (direct), G6PD enzyme assay, chest X-ray. Data was collected, tabulated and analyzed by using Statistical Package for the Social Sciences (SPSS) version 20 and significance was assessed by Chi square test where $p$-value $<0.05$ was considered significant.

\section{Results}

During the period of one year starting from June 01, 2012 to May 31, 2013, there was a total of 19050 live birth born in two hospitals. Of those newborns, 1183 neonates were admitted to nursery and to the NICU. Two hundred cases were enrolled in this study which fulfilled the inclusion criteria. Five readings of the mean were taken and were $9.9 \mathrm{mg} / \mathrm{dl}( \pm 2.9 \mathrm{SD}), 13.1 \mathrm{mg} / \mathrm{dl}( \pm 3.5 \mathrm{SD}), 14 \mathrm{mg} / \mathrm{dl}$ $( \pm 3.8 \mathrm{SD}), 11.4 \mathrm{mg} / \mathrm{dl}( \pm 3.7 \mathrm{SD})$, and $7.3 \mathrm{mg} / \mathrm{dl}$ $( \pm 2.4 \mathrm{SD})$ respectively. The mean peak of total serum bilirubin of the five readings was $16.3 \mathrm{mg} / \mathrm{dl}$ $( \pm 2.9 \mathrm{SD})$. Neonatal sepsis was the most common aetiology and associated risk factor and was present in $70 \%$ of cases. ABO incompatibility was present in $14 \%$ of cases. $\mathrm{Rh}$ incompatibility was present in $8 \%$ of the cases. Cephalohaematoma (excessive bruising) was present in $6 \%$ of the cases. G6PD deficiency was present in $2 \%$ of the cases. The incidence in Preterm babies was higher than fullterm babies and were $73 \%, 27 \%$, respectively. There was a male predominance as males represented $64 \%$ of the cases. Pathological hyperbilirubinemia was more common in low birth weight $\leq 2.5 \mathrm{~kg}$ and represented $80 \%$ of the cases. History of pathological jaundice in siblings was present in $7 \%$ of the cases. Infant of diabetic mother represented $5 \%$ of the cases, see (Fig. 1). The neonatal sepsis was higher in preterm babies $82 \%$ than fullterm babies $18 \%$, and this difference was statistically significant $(p=0.000)$. ABO incompatibility was higher in fullterm babies $52 \%$ in comparison to preterm babies $48 \%$, and this difference was statistically significant ( $p=0.002)$. G6PD deficiency was found in fullterm babies $100 \%$, and was statistically significant $(p=0.02)$. Rh incompatibility was high in preterm babies $56 \%$ than fullterm babies $44 \%$, and this difference was not statistically significant ( $p=0.1$ ), see (Fig. 2). The risk factors in relation to the mean total serum bilirubin (TSB) of five readings was high in $\mathrm{Rh}$ incompatibility followed by $\mathrm{ABO}$ incompatibility, neonatal sepsis, cephalohaematoma and G6PD deficiency and were $17 \mathrm{mg} / \mathrm{dl}( \pm 2.8 \mathrm{SD}), 16.7 \mathrm{mg} / \mathrm{dl}( \pm 3.2 \mathrm{SD}), 16.3 \mathrm{mg} / \mathrm{dl}$ $( \pm 2.8 \mathrm{SD}), 14.9 \mathrm{mg} / \mathrm{dl}( \pm 2.6 \mathrm{SD})$ and $13.5 \mathrm{mg} / \mathrm{dl}$ $( \pm 2.3 \mathrm{SD})$ respectively, and the differences were statistically not significant. The mean total serum bilirubin in preterm babies was $16.5 \mathrm{mg} / \mathrm{dl}( \pm 2.7 \mathrm{SD})$ and in fullterm babies was $15.6 \mathrm{mg} / \mathrm{dl}( \pm 3.3 \mathrm{SD})$, and this difference was statistically not significant $(p=0.05)$. The mean TSB of five reading in male babies were higher than female babies and were $16.3 \mathrm{mg} / \mathrm{dl}( \pm 2.6 \mathrm{SD})$ and higher $16.4 \mathrm{mg} / \mathrm{dl}( \pm 2.8 \mathrm{SD})$ respectively, and this difference was not statistically significant $(p=0.9)$. In low birth weight babies $\leq 2.5 \mathrm{~kg}$, the mean TSB was higher than babies with birth weight $>2.5 \mathrm{~kg}$ and were $16.4 \mathrm{mg} / \mathrm{dl}( \pm 2.8 \mathrm{SD})$, $15.8 \mathrm{mg} / \mathrm{dl}( \pm 3.3 \mathrm{SD})$ respectively, and this difference was statistically not significant $(p=0.3)$. The mean TSB was high in babies with siblings who have history of pathological jaundice and was $17.7 \mathrm{mg} / \mathrm{dl}( \pm 2.4 \mathrm{SD})$, and this difference was statistically not significant $(p=0.05)$. Also, the mean TSB in infant of diabetic mother was high and was statistically not significant ( $p=0.05$ ). In our study, we found that all cases were treated by phototherapy. Only two cases were found to be treated by exchange transfusion (1\%). In the current study the outcome of the cases was as follows, $83 \%$ of the cases were discharged in good condition, $4 \%$ were discharged against medical advice (DAMA), and $13 \%$ of the cases passed away. In the present study, we found that $13 \%$ of the cases who passed away had neonatal sepsis. Out of them, $12 \%$ were preterm babies and $1 \%$ were fullterm babies. 
Table (1): The risk factors of pathological unconjugated hyperbilirubinemia in relation to mean total serum bilirubin.

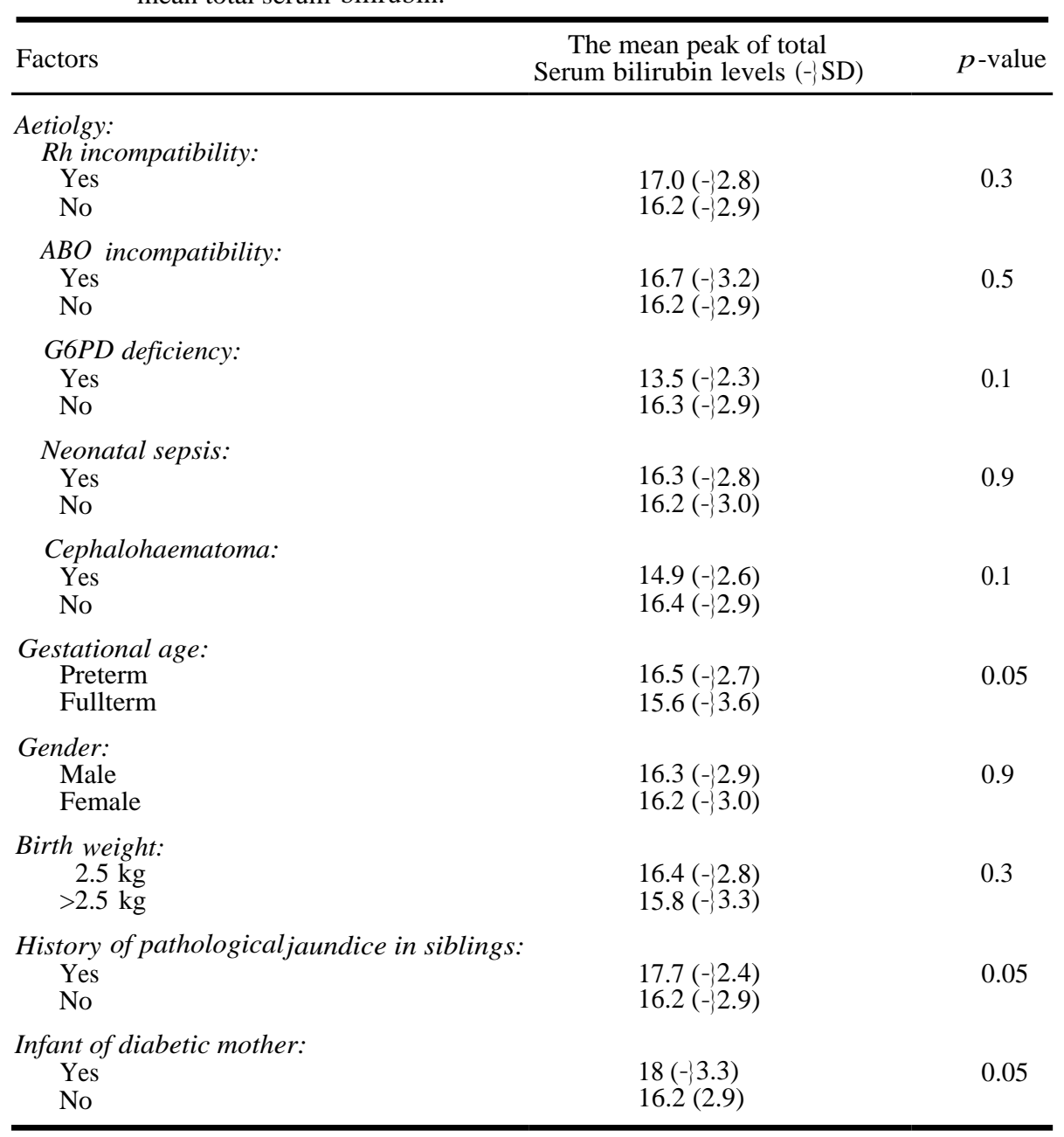

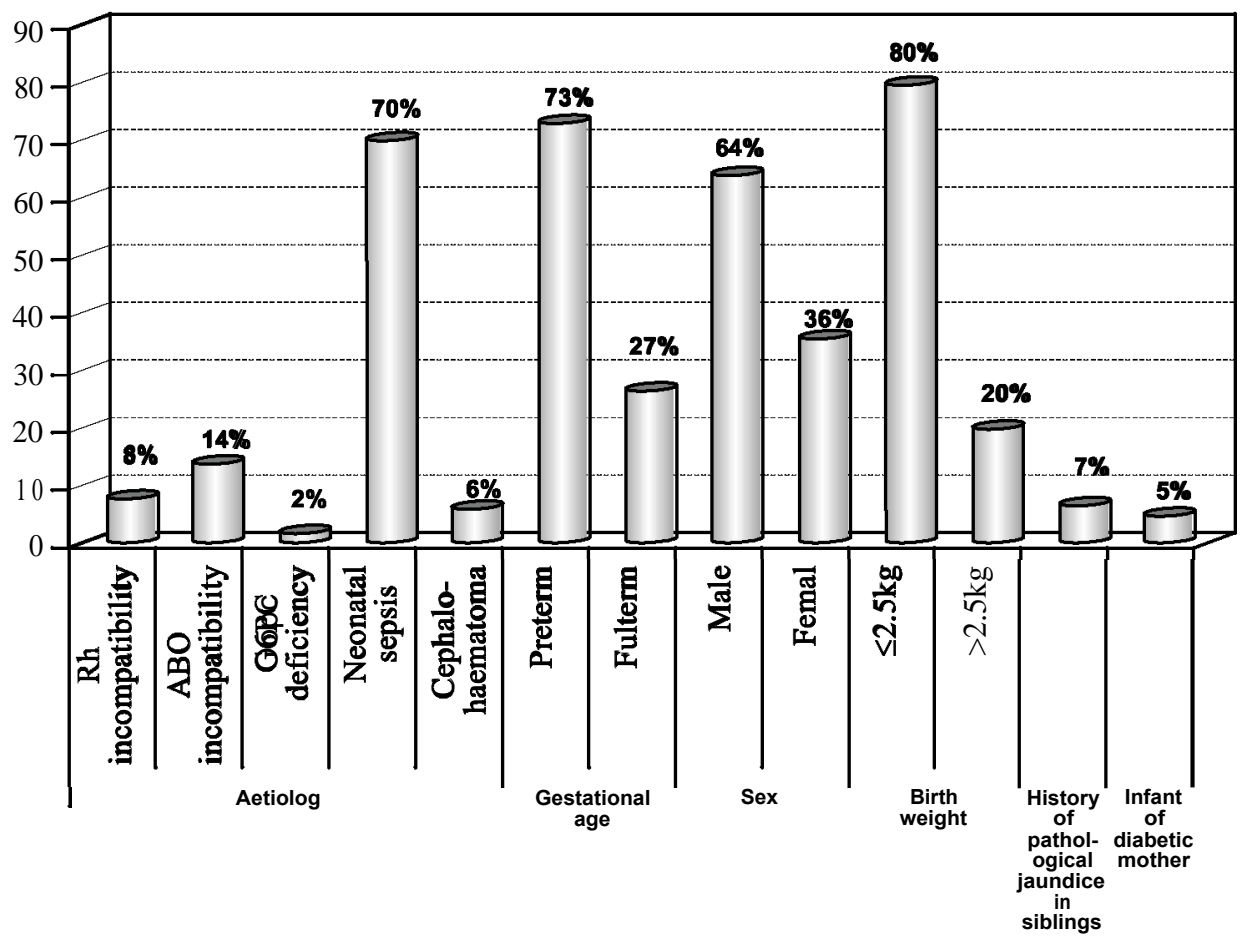

Fig. (1): The risk factors of pathological unconjugated hyperbilirubinemia. 


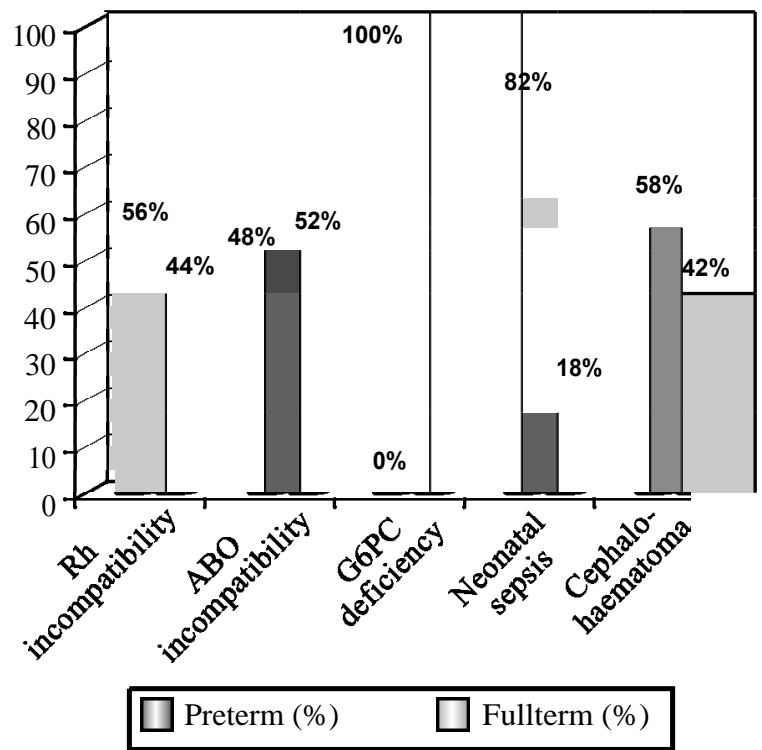

Fig. (2): Aetiology of pathological unconjugated hyperbilirubinemia by gestational age.

\section{Discussion}

Jaundice is a clinical condition that is often present in pediatric practice and constitutes one of the major issues within the neonatal period. It can be both physiological and pathological processes in newborns [1]. In our study, the incidence of pathological unconjugated hyperbilirubinemia was $(16.9 \%)$ of newborn admitted to the NICU in the two hospitals and this is in agreement with the results reported by Sarici et al., [5] . Olusanya et al., reported that the incidence of infants that were admitted to the NICU and had pathologic jaundice were $6.7 \%$ [7]. Our study revealed that $73 \%$ of the cases were preterm and $27 \%$ of the cases were fullterm, and this is in agreement with a study conducted by Kavitha et al., [8] . In contrast to our study, Iacob D et al., reported that $71.42 \%$ of cases were fullterm and $28.57 \%$ of cases were preterm [9]. In our study, there was a male predominance as males represented $64 \%$ of the cases, with male to female ratio being 1.8:1. This is in agreement with studies conducted by Zabeen et al. and HennyHarry and Trotman [10,11]. In contrast to our study, Kavitha et al., 2016 found that a female predominance was present in $56.6 \%$ of the cases [8]. In the present study the pathological hyperbilirubinemia was more common in low birth weight $<2.5 \mathrm{~kg}$ than in those with birth weight $>2.5 \mathrm{~kg}$ and represented $80 \%, 20 \%$ of the cases respectively. This is similar to what has been reported by Kavitha et al. [8] in his study which showed that the incidence of pathological jaundice was found to be more in low birth weight babies with a weight less than $2.5 \mathrm{~kg}$ $80 \%$ compared to $20 \%$ in those who had weight above $2.5 \mathrm{~kg}$. Abdolahad et al. and Medhi et al., reported that the history of pathological jaundice in the siblings has observed to be $13.5 \%$ and $12.2 \%$ of cases respectively $[\mathbf{1 , 1 2}]$. In our study, we found that $7 \%$ of the cases had history of pathological jaundice in the siblings. Plotz postulated that this may be due to the repetition of blood group incompatibility within the family, or other familial conditions including glucose-6-phosphate dehydrogenase (G6PD) deficiency and hereditary spherocytosis [13] . Pathological jaundice in our study was found in $5 \%$ of the cases in infant of diabetic mother (IDM), and this is in accordance to what has been reported by Arrif and Bhutta which found that only $3.3 \%$ of cases were IDM [14]. In contrast to our study, Zabeen et al., found that $35 \%$ of cases were IDM [10]. The higher incidence might be that their study had a higher number of diabetic mothers who delivered their babies at the hospital. In the present study, neonatal sepsis was the commonest aetiology and associated risk factor of pathological hyperbilirubinemia. This is in agreement with Kavitha et al., study which found that neonatal sepsis was found as a major associated risk factor in neonates with jaundice [8]. This is explainable because the majority of neonates who had sepsis were preterm and had low birth weight [15]. ABO incompatibility was observed in $14 \%$ of the cases. This is similar to what has been reported by Singhal et al., who found that $14.3 \%$ of cases were associated with $\mathrm{ABO}$ incompatibility [16]. In contrast to our study, Henny-Harry and Trotman found that $\mathrm{ABO}$ incompatibility was present in $35 \%$ of cases [11]. $\mathrm{Rh}$ incompatibility was found in $8 \%$ of the pathological jaundice cases; these results were similar to what has been reported by Medhi et al., and Singhal et al. [1,16]. In contrast to our study, Haque et al., 2004 found that $34 \%$ of cases had $\mathrm{Rh}$ incompatibility [17]. In this study, G6PD deficiency was observed in $2 \%$ of the cases, and this is nearly similar to what has been reported by Kavitha et al. [8] . In contrast to our study, Verle et al. found that the prevalence of G6PD deficiency was high as $31 \%$ of the cases [18].

Cephalohematoma was present in $6 \%$ of cases with pathological jaundice and this is in agreement with Najib et al. and Medhi [19,1]. In our study, we found that the neonatal sepsis was more common in preterm babies than in fullterm babies and this was highly statistically significant $(p=0.000$ ). This in contrast to what has been reported by a study done by Rasul et al., which found that there is no correlation between prematurity and sepsis [20]. In our study, $\mathrm{ABO}$ incompatibility was significantly higher in fullterm babies $(p=0.002)$. This is similar to what have been reported by Zabeen et al. [10] 
Also, in this study we found that $\mathrm{Rh}$ incompatibility were more common in preterm babies than in fullterm babies and this was statistically not significant $(p=0.1)$. This is in agreement with the results that were reported by Zabeen et al. [10]. In the present study, we found that patients with $\mathrm{ABO}$ incompatibility were more than those with $\mathrm{Rh}$ incompatibility. The incidence of $\mathrm{Rh}$ incompatibility has decreased as a result of the introduction of $\mathrm{Rh}$ (D) immunoglobulin to Rh-negative mothers. In the current study, the mean total serum bilirubin level was $16.3 \mathrm{mg} / \mathrm{dl}( \pm 2.9 \mathrm{SD})$. This is nearly similar to what has been reported by Zabeen et al., who found that the mean TSB was $15.4 \mathrm{mg} / \mathrm{dl}( \pm 2.3 \mathrm{SD})$ [10]. The mean total serum bilirubin was higher in cases with $\mathrm{Rh}$ incompatibility than in $\mathrm{ABO}$ incompatibility cases and this difference was statistically not significant $(p>0.05)$. This is in agreement with results reported by Cherepnalkovski et al. [21]. In our study, there was no significant correlation between mean total serum bilirubin and neonatal gender. The lack of significant correlation is similar to what has been reported by Agarwal et al but in contrast to our results, Garosi et al., 2016 found that there was a positive relationship between jaundice and neonate's gender [22,23] .

Also, there was no significant correlation between mean total serum bilirubin and birth weight. This is in agreement with Agarwal et al., who proved that there was no statistical significance in serum bilirubin of neonates with birth weights below $2.5 \mathrm{~kg}$ and those with birth weight above $2.5 \mathrm{~kg}$ [22]. The mean total serum bilirubin was high in those babies who had history of pathological jaundice in their siblings, and this is in agreement with Singh et al. [24].

\section{Conclusions:}

Pathological unconjugated hyperbilirubinemia is one of the major problems in neonatal morbidity and mortality in Yemen. Neonatal sepsis was the commonest aetiology and associated risk factor of pathological hyperbilirubinemia and the major cause of death in our study. Most cases were treated by intensive phototherapy which was effective in reducing the need for using exchange transfusion in our study.

\section{Recommendations:}

- Early screening, detection of hyperbilirubinemia and appropriate management should be endorsed in the health system policy as it will help in decreasing the incidence of hyperbilirubinemia.

- Pregnant women should be encouraged to visit the antenatal care clinic as early as possible and attend consistently to prevent and reduce complications of maternal illnesses during pregnancy.

- Pregnant women should be encouraged to deliver in a professional environment, either under the supervision of skilled birth attendant or in health centers or in hospitals as it will allow early medical intervention which will consequently reduce the risk factors of hyperbilirubinemia.

- Strict hand washing should be practiced; strict asepsis should be followed during delivery. By following these simple measures sepsis can be prevented.

- Intensive phototherapy should be provided in health centers and hospitals and utilized as soon as needed as it was effective in reducing the need for exchange transfusion.

- Modern health facilities should be provided by the Ministry of Health to public hospitals.

- A national protocol for early essential neonatal care and resuscitation should be adopted and followed as a guide in neonatal health units.

- Regular refreshment training courses should be provided nationally to health workers in neonatal health units.

- Health workers should be incentivized to pursue neonatal specialties to increase the number of specialized doctors and nurses in newborn care.

- Monitoring and evaluation of the quality of the health services should be maintained in the Ministry of Health.

\section{References}

1- MEDHI G., SONI S. and DAS H.: Incidence, Course, Outcome and Prediction of Significant Hyperbilirubinemia in Newborn. IOSR Journal of Dental and Medical Sciences (IOSR-JDMS), 15 (4): 40-46, 2016.

2- DEORARI A.K.: Unconjugated Hyperbilirubinemia in Newborns. Indian Pediatrics, 39: 30-42, 2002.

3- MEREDITH L. PORTER and BETH L. DENNIS: Hyperbilirubinemia in the Term Newborn. Am. Fam. Physician, 65 (4): 599-607, 2002.

4- DENNERY P.A., SEIDMAN D.S. and STEVENSON D.K.: Neonatal hyperbilirubinemia. New Engl. J. Med., 344: 581-590, 2001.

5- SARICI S.U., SERDAR M.A., KORKMAZ A., ERDEM G., ORAN O., TEKINALP G., YURDAKÖK M. and YIGIT S.: Incidence, course, and prediction of hyperbilirubinemia in near-term and term newborns. Pediatrics, 113: 775-780, 2004.

6- American Academy of Pediatrics: Subcommittee on Hyperbilirubinemia. Management of hyperbilirubinemia in the newborn infant 35 or more weeks of gestation. Pediatrics, 114 (1): 297-316, 2004.

7- OLUSANYA B.O., AKANDE A.A., EMOKPAE A. and OLOWE S.A.: Infants with severe neonatal jaundice in 
Lagos, Nigeria: Incidence, correlates and hearing screening outcomes. Tropical Medicine and International Health, 14: 301-310, 2009

8- KAVITHA V., BOLLIPO S. and VARAHALA A.M Clinical Study of Pathological Jaundice in Newborns. IOSR Journal of Dental and Medical Sciences (IOSRJDMS), 15 (3): 58-63, 2016.

9- IACOB D., BOIA M., IACOB R.E. and MANEA A.: Neonatal jaundice-Etiology and incidence. Jurnalul pediatrului, Vol. xiv: 55-56, 2011.

10- ZABEEN B., NAHAR J., NABI N., BAKI A., TAYYEB S., AZAD K. and NAHAR N.: Risk factors and outcome of neonatal jaundice in a tertiary hospital. Ibrahim Med. coll. J., 4 (2): 70-73, 2010.

11- HENNY-HARRY C. and TROTMAN H.: Epidemiology of neonatal jaundice at the University Hospital of the West Indies. West Indian Med. J., 61 (1): 37-42, 2012.

12- ABDOLAHAD A., KAMYAR G., MOHAMMADALI S.M. and HOSSEIN K.: Neonatal jaundice: Knowledge and practice of Iranian mothers with icteric newborns. Pakistan Journal of Biological Sciences, 11: 942-945, 2008.

13- PLOTZ R.D.: Familial occurrence of hemolytic disease of the newborn due to AO blood group incompatibility. Hum. Pathol., 16: 113-116, 1985

14- ARRIF K. and BHUTTA Z.A.: Risk factors and spectrum of neonatal jaundice in a birth cohort in Karachi. Indian Pediatr., 36 (5): 487-93, 1999.

15- KOREJO H.B., BHURGRI G.R., BHAND S., QURESHI M.A., DAHRI G.M. and CHOHAN R.K.: Risk factors for kernicterus in neonatal jaundice. Gomal Journal of Medical Sciences, 8 (1): 12-15, 2010.

16- SINGHAL P.K., SINGH M., PAUL V.K., DEORARI A.K and GHORPADE M.G.: Spectrum of neonatal hyperbilirubinemia: An analysis of 454 cases. Indian Pediatr. 29: $319-325,1992$
17-HAQUE M.M., HOSSAIN M.M., HASSAN M.Q., UDDIN A.S.M.N., BEGUM J.A. and CHOWDHURY M.A.K.: Neonatal hyperbilirubinemia requiring exchange transfusion management and outcome. Bang J. Child Health, 28: 55-59, 2004.

18- VERLE P., NHAN D.H., TINH T.T., UYEN T.T., THUONG N.D., KONGS A., STUYFT P. and COOSEMANS M.: Glucose-6- phosphate dehydrogenase deficiency in northern vietnam. Tropical Medicine \& International Health, 5: 203-6, 2000

19- NAJIB K.S., SAKI F., HEMMATI F. and INALOO S. Incidence, Risk Factors and Causes of Severe Neonatal Hyperbilirubinemia in the South of Iran (Fars Province). Iranian Red Crescent Medical Journal, 15 (3): 260-3, 2013.

20- RASUL C.H., HASAN M.A. and YASMIN F.: Outcome of Neonatal Hyperbilirubinemia in a Tertiary Care Hospital in Bangladesh. Malays J. Med. Sci., 17 (2): 40-44, 2010.

21- CHEREPNALKOVSKI P.A., KRZELJ V., IVANOVSKA B.Z., GRUEV T., MARKIC J., ALULOSKA N. ZDRAVESKA N. and PIPERKOVSKA K.: Evaluation of Neonatal Hemolytic Jaundice: Clinical and Laboratory Parameters. Open Access Maced J. Med. Sci., 3 (4): $694-$ 698, 2015

22- AGARWAL V., SINGH V., GOEL S.P. and GUPTA B. Maternal and neonatal factors affecting physiological jaundice in western U.P. Indian J. Physiol. Pharmacol., 51: 203-206, 2007.

23- GAROSI E., MOHAMMADI F. and RANJKESH F.: The Relationship between Neonatal Jaundice and Maternal and Neonatal Factors. Iranian Journal of Neonatology, 7 (1): $37-40,2016$.

24- SINGH H., AHMED A. and GOPALKRISHNA P.V.: Approach to Hyperbilirubinemia in Near Term Infants. International Journal of Contemporary Medical Research, 3 (6): 1630-1634, 2016. 


\section{عوامل الخطر لفرط خضاب الدم البيليروبين

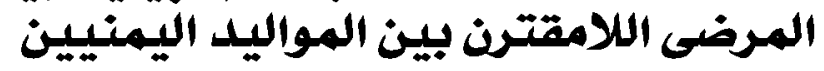

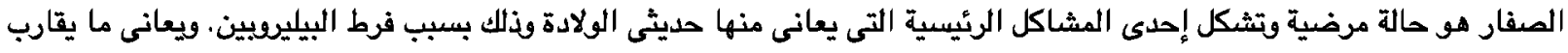

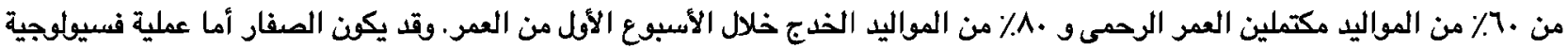

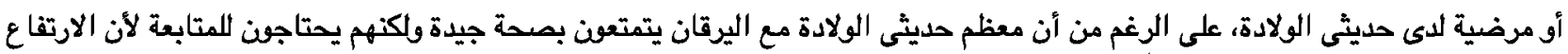

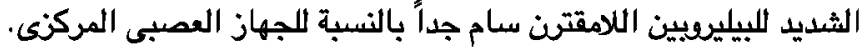

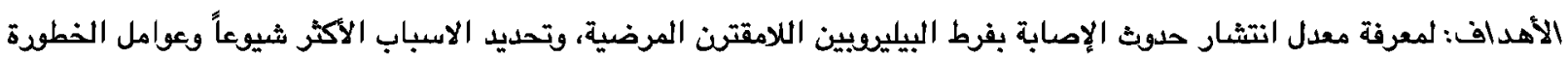

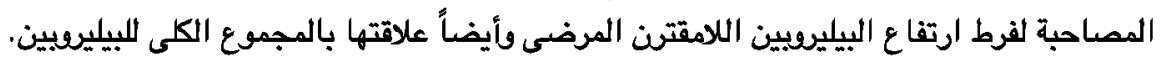

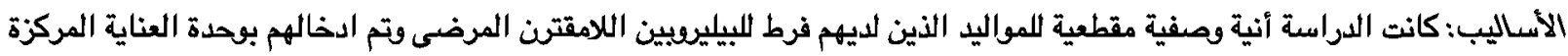

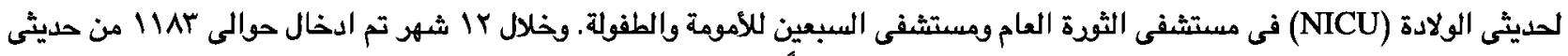

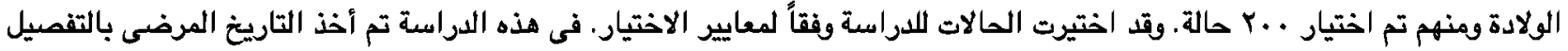

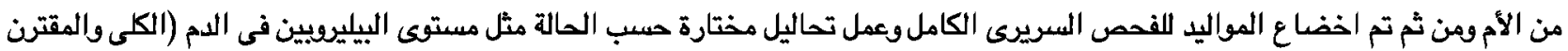

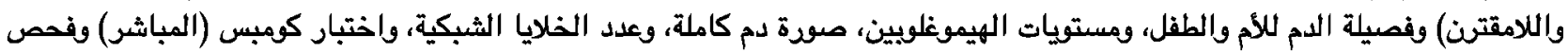

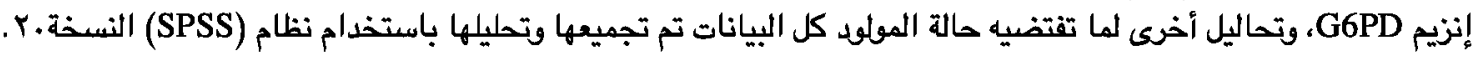

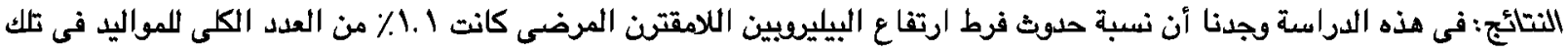

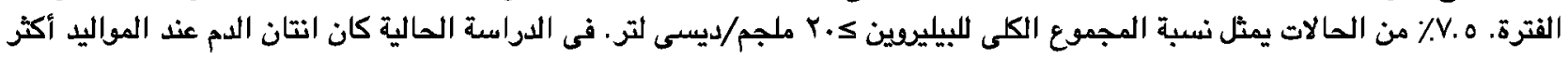

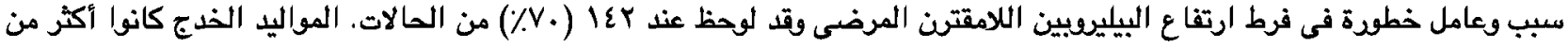

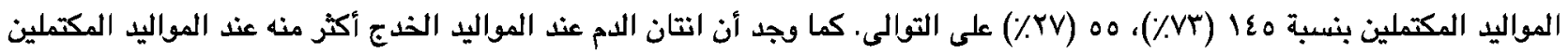

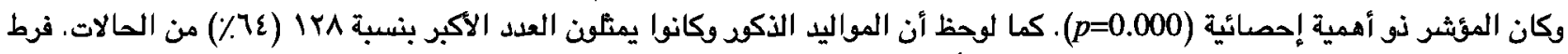

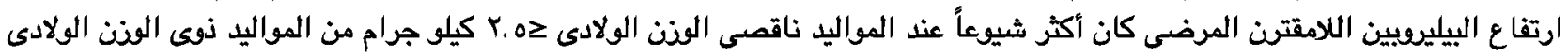

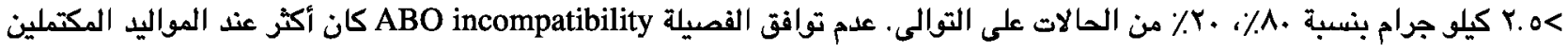

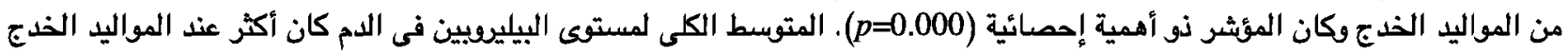

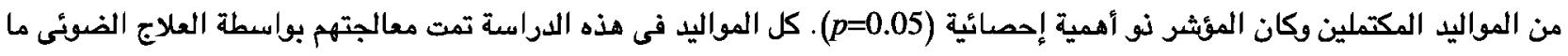

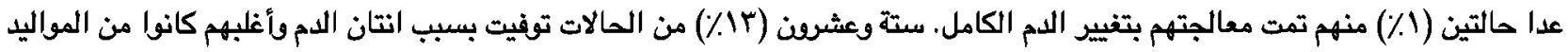

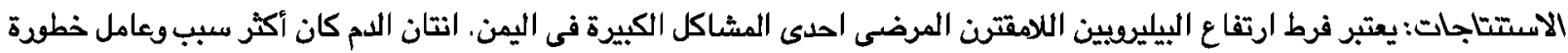

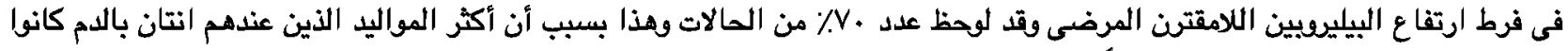

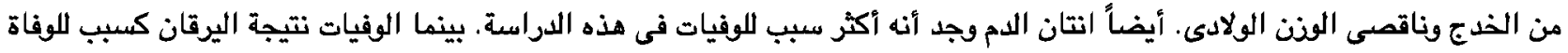

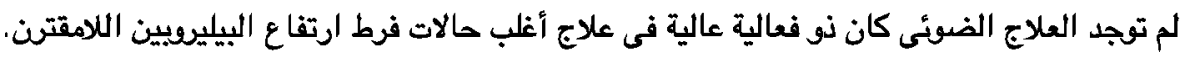

